\title{
Protective System Problem Identified
}

National Cancer Institute

\section{Source}

National Cancer Institute. Protective System Problem Identified. NCI Thesaurus. Code C92098.

Problems related to the system(s) designed to prevent or warn about unsafe operation of the device. 